\title{
Involucrin, but not filaggrin and Kdap mRNA, expression is downregulated in 3-D cultures of intact rat hair bulbs after calcium stimulation
}

\author{
Justyna Niderla-Bielińska, Stanisław Moskalewski \\ Department of Histology and Embryology, Medical University of Warsaw, Poland
}

\begin{abstract}
The hair follicle consists of several distinctive epidermal cell layers. The hair root, which undergoes keratinization, is surrounded by two sheaths: the inner root sheath (IRS) and the outer root sheath (ORS). The ORS is continuous with the basal layer of the epidermis. Its cells do not keratinize in situ, unlike IRS. We have previously demonstrated that keratinization of the ORS was prevented by contact with the IRS in hair follicle mid-segments (i.e. fragments dissected from skin at the level above the hair bulb and below the opening of the sebaceous gland duct) cultured on agarose layer. The purpose of this study was to determine whether the same applies to the hair bulb. After isolation, intact bulbs or hair bulb-derived cells were incubated in suspension in a low or high calcium medium. The level of mRNA for differentiation markers: involucrin, filaggrin, keratinocyte differentiation associated protein and trichohyalin, was studied by RealTime PCR. We observed increased $\mathrm{Ca}^{2+}$ upregulated expression of involucrin, filaggrin, trichohyalin and Kdap in cultures of bulb-derived cells, but in hair bulbs downregulation of involucrin and trichohyalin was observed. We concluded that the inner root sheath exerts an inhibitory effect on the expression of involucrin and trichohyalin already in the hair bulbs. The observation that downregulation of involucrin expression under $\mathrm{Ca}^{2+}$ influence occurs both in hair bulb and midsegments could simplify future experiments, since their separation does not seem to be necessary. (Folia Histochemica et Cytobiologica 2011, Vol. 49, No. 2, 335-343)
\end{abstract}

Key words: hair follicle, outer root sheath, inner root sheath, hair bulb, involucrin

\section{Introduction}

The hair follicle in the anagen stage consists of several distinctive, concentrically arranged epidermal layers and surrounding dermal tissue (Figure 1). Hair medulla, cortex and cuticle constitute the hair root and undergo keratinization. The hair root is encircled by the inner root sheath (IRS) which consists of cuticle, Huxley's and Henle's layers. All layers of the IRS form trichohyalin granules and keratinize, beginning with Henle's layer. Huxley's layer is the last to keratinize. Within this layer so called 'winged' cells

Correspondence address: J. Niderla-Bielińska,

Department of Histology and Embryology,

Medical University of Warsaw,

Chalubinskiego Str. 5, 02-004 Warsaw, Poland;

tel.: (+ 48 22) 62952 82, fax: (+ 48 22) 62952 82;

e-mail: justynan@ib.amwaw.edu.pl could be observed. Their thick processes squeeze among fully keratinized Henle's layer cells and reach the outer root sheath (ORS). The ORS is composed of outermost (basal) cell layer, which may be considered the 'true' ORS and the innermost layer, also known as the companion cell layer $[1,2]$. The ORS is continuous with the basal layer of epidermal epithelium but is incapable of producing spinous, granular, or cornified cells such as those found in the epidermis [3]. The ORS originates, similarly as with other hair follicle components, from slow-cycling or label-retaining cells present in the bulge region located beneath the sebaceous gland $[1,4-6]$. The basal layer of the outer root sheath serves as the pathway for migration of cells from the bulge towards the hair bulb [1]. It can be observed already in the upper hair bulb region $[7,8]$. The companion layer is characterized by the presence of type II cytokeratin $\operatorname{K} 6 \mathrm{hf}[9,10]$ and calretinin [11]. It is attached to the IRS by des- 


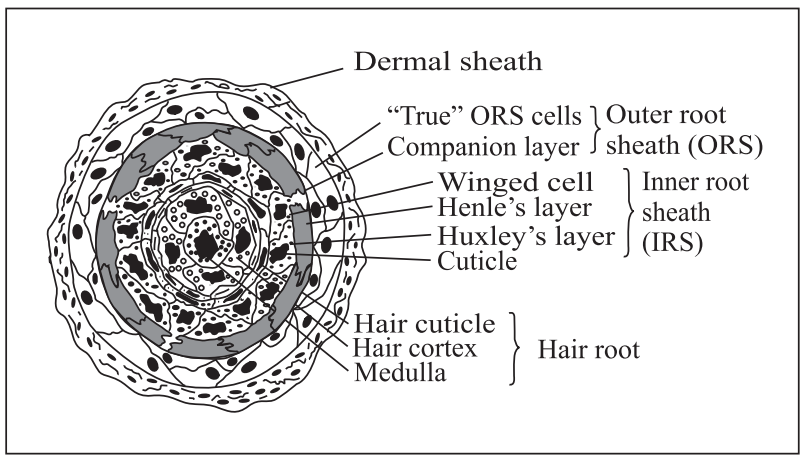

Figure 1. Schematic presentation of the transverse section of hair follicle at the level above hair bulb

mogleins 1 and 3 [12] and may be engaged in the differentiation of Henle's cells [2]. Furthermore, according to Rogers [7], the innermost (companion) layer of the ORS slides over its outermost layer and thus moves up with the IRS. This observation is important for understanding the mechanism of hair growth.

Since keratinization of the ORS has been observed in various types of in vitro cultures [13-16], we attempted in the previous study to find out why the ORS cells fail to keratinize in situ. The ORS cells from mid-segments of rat hair follicle separated from the IRS responded in monolayer culture to $\mathrm{Ca}^{2+}$ stimulation with an increased expression of involucrin, filaggrin and keratinocyte differentiation associated protein (Kdap), generally recognized as keratinocyte differentiation markers [17-20].

In ORS cells adhering to the IRS in 3-D cultures of mid-segments, $\mathrm{Ca}^{2+}$ medium enrichment upregulated the expression of filaggrin and Kdap and downregulated the expression of involucrin [21]. Thus, contact with IRS prevented keratinization of the ORS inhibiting production of involucrin, one of the essential components of the cornified envelope [17, 22-24]. The mechanism of this inhibition could depend either on release of a soluble factor from the IRS influencing ORS cells, or by direct cell-to-cell contact of both sheaths in intact hairs [21].

The structure of the ORS in the lower area of the hair bulb differs from that in the mid-segment. It appears to be single layered and seems to touch Henle's layer, recognizable by the presence of trichohyalin granules, without intervention of the companion layer [3]. This layer appears in the upper bulb region [7] and the ORS becomes double-layered [3]. In the mid-segment of rat hair follicles, both the ORS and companion layer often occur as multilayer [3]. Furthermore, IRS in the hair midsegment contains nearly completely differentiated cells of the Henle's layer connected with still in- completely keratinized Huxley's cells [3, 25, 26], while in the hair bulb region differentiation of IRS cells as evidenced by formation of trichohyalin droplets is at an early stage [3,27].

In view of these differences between ORS morphology, and its relation to the IRS in various segments of hair follicle, we wanted to establish whether the response of ORS cells from hair bulb to $\mathrm{Ca}^{2+}$ enriched medium is similar to that described previously for mid-segment ORS. Thus, in the present work, whole hair bulbs and the cells derived from hair bulbs were cultured on agarose layer, which does not allow attachment of cells, in the medium with low or high $\mathrm{Ca}^{2+}$ content. Then the expression of mRNA for keratinocyte differentiation markers: involucrin, filaggrin and Kdap was studied. To find out whether companion layer cells are present in primary cultures of hair bulb-derived cells, calretinin and K6hf positive cells were identified with appropriate antibodies. Because cells derived from hair bulbs would probably originate both from the ORS and hair matrix cells differentiating into IRS, the expression of trichohyalin was also studied.

\section{Material and methods}

Isolation of hair follicle bulbs. Animal experiments have been approved by the Institutional Review Board.

Hair follicles were obtained from female Wistar Albino Glaxo (WAG) rats aged five weeks. Hair follicles of Wistar rats at this age synchronously enter the second anagen which passes into the second telogen at about ten weeks [28]. The animals were euthanized by cervical dislocation, shaved and kept in PBS with $10 \%$ of antibiotic/ /antimycotic solution (Gibco Invitrogen, Carlsbad, CA, USA) at $37^{\circ} \mathrm{C}$ for 45 minutes. The skin from the back was removed, cleared of subcutaneous fat tissue and muscle, and dissected with a sharp knife into three layers (Figure 2). The superficial layer of the skin separated at the level below sebaceous glands and the middle layer in which midsegments of hairs predominated were discarded. The deep layer containing hair bulbs was digested with $2 \mathrm{mg} / \mathrm{ml} \mathrm{col-}$ lagenase and $1 \mathrm{mg} / \mathrm{ml}$ DNase (both from Sigma-Aldrich Chemie, Diesenhofen, Germany) dissolved in PBS at $37^{\circ} \mathrm{C}$ for one hour. Enzymatic solution contained $7 \mathrm{nM}$ TLCK ( $\alpha$-tosyl-L-lysine chloromethyl ketone; Sigma-Aldrich), an inhibitor of clostripain present in collagenase preparations and harmful to cells [29]. After enzymatic treatment, the tissue was put through a $100-\mu \mathrm{m}$ mesh sieve to remove larger fragments of dermis, washed three times with PBS solution and suspended in culture medium. Digested tissue in small batches was inspected under the dissecting microscope and occasionally occurring mid-segments of hairs were removed. 


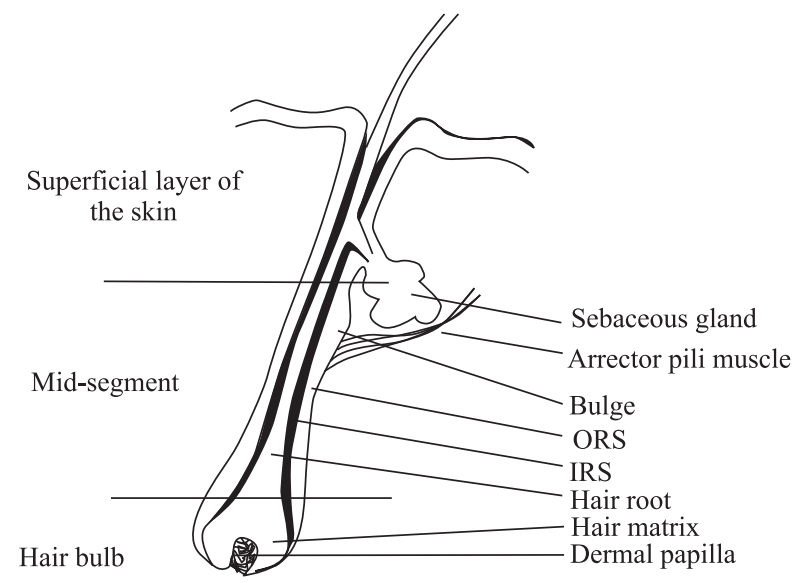

Figure 2. Drawing shows how hair follicle was divided into three parts

Measurement of isolated hair bulb length. Hair bulb length was measured by means of micrometric ocular (PZO, Poland) and Nikon Diaphot-TMD inverted microscope according to the manufacturer's protocol.

Primary cultures of hair bulbs. Suspension of hair bulbs was seeded into $25 \mathrm{~cm}^{2}$ flasks (Corning Inc., Corning, NY, USA) to achieve cell spreading. Cultures were kept in humified atmosphere of $5 \% \mathrm{CO}_{2}$ in air at $37^{\circ} \mathrm{C}$ in Promo-Cell Keratinocyte Growth Medium with low calcium content, further referred to as a standard medium, devised by the producer (PromoCell GmbH, Heidelberg, Germany). Supplements added to this medium included bovine pituitary extract $0.4 \%$, epidermal growth factor $0.125 \mathrm{ng} / \mathrm{ml}$, insulin $5 \mu \mathrm{g} / \mathrm{ml}$, hydrocortisone $0.33 \mu \mathrm{g} / \mathrm{ml}$, transferrin $10 \mu \mathrm{g} / \mathrm{ml}$, epinephrine $0.39 \mu \mathrm{g} / \mathrm{ml}, \mathrm{CaCl}_{2} 0.1 \mathrm{mM}$ and antibiotic/antimycotic solution. Some hair bulbs were also seeded into a 24-well culture plate with coverslips in the wells. After 72 hours, primary cultures were either fixed for immunohistochemistry or detached with trypsin-EDTA (Gibco) and rinsed with PBS containing $0.8 \mathrm{mg} / \mathrm{ml}$ of trypsin inhibitor (Sigma). The cells were suspended in a standard medium.

Secondary cultures of hair bulb-derived cells. Cell suspension in the standard medium was seeded into 24 well culture plates with coverslips in the wells at $10^{5}$ cells per well. After 48 hours, the cells were fixed for immunohistochemistry.

Immunohistochemical detection of trichohyalin, calretinin and K6hf in primary and secondary cultures. For trichohyalin, calretinin and K6hf detection, hair bulbs or hair bulb-derived cells cultured on coverslips were fixed in $2 \%$ paraformaldehyde for 15 minutes. For calretinin detection, cultures were incubated in $1.5 \mathrm{mM} \mathrm{CaCl}_{2}$ enriched medium for 24 hours before fixation, to obtain calcium-induced changes in calretinin conformation [30]. As controls for trichohyalin and K6hf served fragments of hairy skin and for calretinin cerebral cortex [31]. Tissues were fixed in paraformaldehyde for 24 hours, embedded in paraffin and sectioned at $5 \mu \mathrm{m}$. Cultures or tissue sections were heated in a microwave oven according to the method of Manabe et al. [32] and treated with antitrichohyalin AE 15 monoclonal antibody (kindly provided by Dr. T.T. Sun, [33]) diluted 1:5 or with anti-K6hf monoclonal antibody (Progen $\mathrm{GmbH}$, Heidelberg, Germany) diluted 1:50 for 60 minutes at room temperature. Calretinin was detected with polyclonal antibody (GeneTex Inc., Irvine, CA, USA) diluted 1:10 and incubated for 60 minutes at room temperature. The secondary antibody was biotinylated rabbit $F\left(a^{\prime}\right)_{2}$ fragments of anti-mouse $\mathrm{IgG}$ or biotinylated swine $\mathrm{F}\left(\mathrm{ab}{ }^{\prime}\right)_{2}$ fragments of anti-rabbit IgG diluted 1:400 (DakoCytomation, Glostrup, Denmark). Reaction was completed with extravidin-peroxidase conjugate (DakoCytomation) and diaminobenzidine tablets (Sigma-Aldrich). In controls, $0.1 \%$ mouse serum was used instead of the first antibody.

Culture of whole hair bulbs in $\mathrm{Ca}^{2+}$ enriched medium. For estimation of initial expression of differentiation markers, we used hair bulbs studied immediately after isolation. For study of $\mathrm{Ca}^{2+}$ influence, freshly isolated hair bulbs were suspended in a standard or $1.5 \mathrm{mM} \mathrm{CaCl}_{2}$ enriched medium, put into 12 well culture plates (Corning) with agarose-covered bottoms and incubated for 12 and 24 hours. Three per cent agarose (Sigma) with a gelling point of $37^{\circ} \mathrm{C}$, dissolved in $\mathrm{PBS}$ at $95^{\circ} \mathrm{C}$, was used.

\section{Culture of hair bulb-derived cells in $\mathrm{Ca}^{2+}$ enriched me-}

dium. Suspension of cells from primary cultures of hair bulbs was either immediately used for RNA isolation or transferred into agarose covered wells of 12 well culture plates. The cells were seeded at $0.5 \times 10^{6}$ cells per well and cultured in a standard or $1.5 \mathrm{mM} \mathrm{CaCl}_{2}$ enriched medium for 12 and 24 hours. Phase contrast photographs of cultures were taken with a Nikon Diaphot-TMD inverted microscope.

Total RNA isolation. RNA was isolated with NucleoSpin ${ }^{\circledR}$ RNA II kit (Macherey-Nagel, Neumann-Neander, Duren, Germany), according to the manufacturer's protocol. The quality of isolated RNA was checked by electrophoresis in $1 \%$ agarose denaturing gel containing $6 \%$ formaldehyde and buffered with MOPS (Sigma). After electrophoresis, the gel was scanned with digital imaging system GDS9000 using GRAB-IT 2.0 software (UVP, Cambridge, UK).

Reverse transcription (RT). RT was carried out in $20 \mathrm{ml}$ of a reaction mix containing $1 \times$ transcription buffer, $5.5 \mathrm{mM}$ $\mathrm{MgCl}_{2}, 0.5 \mathrm{mM}$ of deoxynucleosides (dNTP), $2.5 \mu \mathrm{M}$ oligo$\mathrm{dT}$ primer, $3 \mathrm{U}$ of RNase inhibitor and $6 \mathrm{U}$ of reverse tran- 
scriptase (Reverse Transcription Kit, Promega). One microgram of total RNA was heated at $70^{\circ} \mathrm{C}$ for 10 minutes, cooled to $2^{\circ} \mathrm{C}$ and added to the reaction mix. RT was performed in Eppendorf Master Cycler Gradient. Samples were incubated at $42^{\circ} \mathrm{C}$ for two hours and then heated to $94^{\circ} \mathrm{C}$.

Real Time PCR. Real Time PCR was performed in Abi Prism 7500 (Applied Biosystems, Warrington, UK) in 96-well optical plates. Each sample was tripled and supplied with endogenous control (Rat GAPDH Endogenous Control VIC®/MGB Probe). For gene expression, TaqMan Expression Assays were used: for involucrin no. Rn01770918_s1; for filaggrin no. Rn01770905_m1; for Kdap no. Rn01476441_m1; and for trichohyalin no. Rn01409236_s1. All probes were stained with FAM (Applied Biosystems). Reactions were run in $25 \mu$ l volume with TaqMan Universal Master Mix (Applied Biosystems), appropriate primer set, MGB probe and $50 \mathrm{ng}$ of cDNA template. Universal thermal conditions, i.e. ten minutes at $95^{\circ} \mathrm{C}$ and 40 cycles of 15 seconds at $95^{\circ} \mathrm{C}$ and one minute at $60^{\circ} \mathrm{C}$, were used. Data analysis was done with sequence detection software version 1.2 (Applied Biosystems).

Statistical analysis. Statistical analysis was performed using Statistica software ver. 9 (StatSoft, Tulsa, OK, USA). Data is presented as mean and standard deviation from five experiments. A Wilcoxon test was used to compare mRNA expression between groups. A p value of less than 0.05 was considered to be statistically significant.

\section{Results}

\section{Evaluation of isolated hair bulb length}

Isolated hair bulb length varied from $40.54 \mu \mathrm{m}$ to $168.47 \mu \mathrm{m}$, with mean $93.09 \mu \mathrm{m}(\mathrm{SD} \pm 25.31 \mu \mathrm{m})$.

\section{Morphology of the hair bulb primary cultures}

During the first day of culture in the standard medium, numerous hair bulbs attached to the plastic (Figure $3 \mathrm{~A}$ ). On the second day of culture, spreading of hair bulb cells began, and on the third day keratinocytes formed monolayers of cells around bulbs (Figure $3 \mathrm{~B}$ ). Spheroidal structures, described in our previous paper as fat droplets encompassed by cells of the Henle's layer [26], were rarely visible.

\section{Companion layer and matrix cells were present in the primary cultures}

Trichohyalin in hair follicles in control skin sections was expressed in inner root sheath cells and in hair medulla, with K6hf in the companion layer and ma-

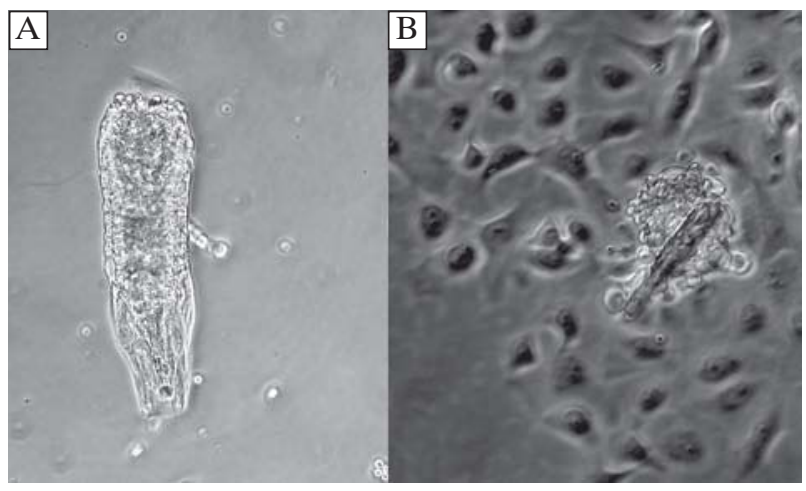

Figure 3. Hair bulbs (A) immediately after isolation and (B) after 72 hours of culture. Phase contrast, $\times 125$. (A) single hair bulb; (B) cells migrating from the hair bulb and forming monolayer

trix cells, in accord with previous descriptions [8, 33]. Calretinin was detected in sections of the cerebellum in some neurons, and in hairy skin in companion layer cells (data not shown). In primary culture of hair bulbs trichohyalin, K6hf and calretinin expression was observed in some cells attached to the hair shaft and in spread keratinocytes (Figures $4 \mathrm{~A}-\mathrm{F}$ ). In the secondary cultures, only a few K6hf positive cells were detected (data not shown).

\section{Calcium induced morphological changes in agarose cultures of hair bulb-derived cells}

After transfer of keratinocytes derived from hair bulbs onto agarose layer into standard medium, the cells either floated in the medium or occasionally formed clusters composed of several cells. In the medium enriched with $1.5 \mathrm{mM} \mathrm{Ca}^{2+}$, clusters were multicellular and more numerous (Figures 5A-B).

\section{Expression of involucrin mRNA in whole hair bulbs cultured on agarose layer is downregulated in $\mathrm{Ca}^{2+}$-enriched medium}

Expression of involucrin and trichohyalin mRNA in hair bulbs cultured on agarose layer for 12 or 24 hours in the standard medium was decreased in comparison with freshly isolated specimens. $\mathrm{Ca}^{2+}$ enriched medium had a slightly stimulatory effect on involucrin (Figure 6A) and trichohyalin (Figure 6C) expression in comparison with hair bulbs cultured in the standard medium after 12 hours, but the level of mRNA was much lower than in freshly isolated hair bulbs; after 24 hours the effect was not evident. In the case of filaggrin (Figure 6B), cultivation of hair bulbs in the standard medium exerted a strong stimulatory effect already after 12 hours and was also evident af- 

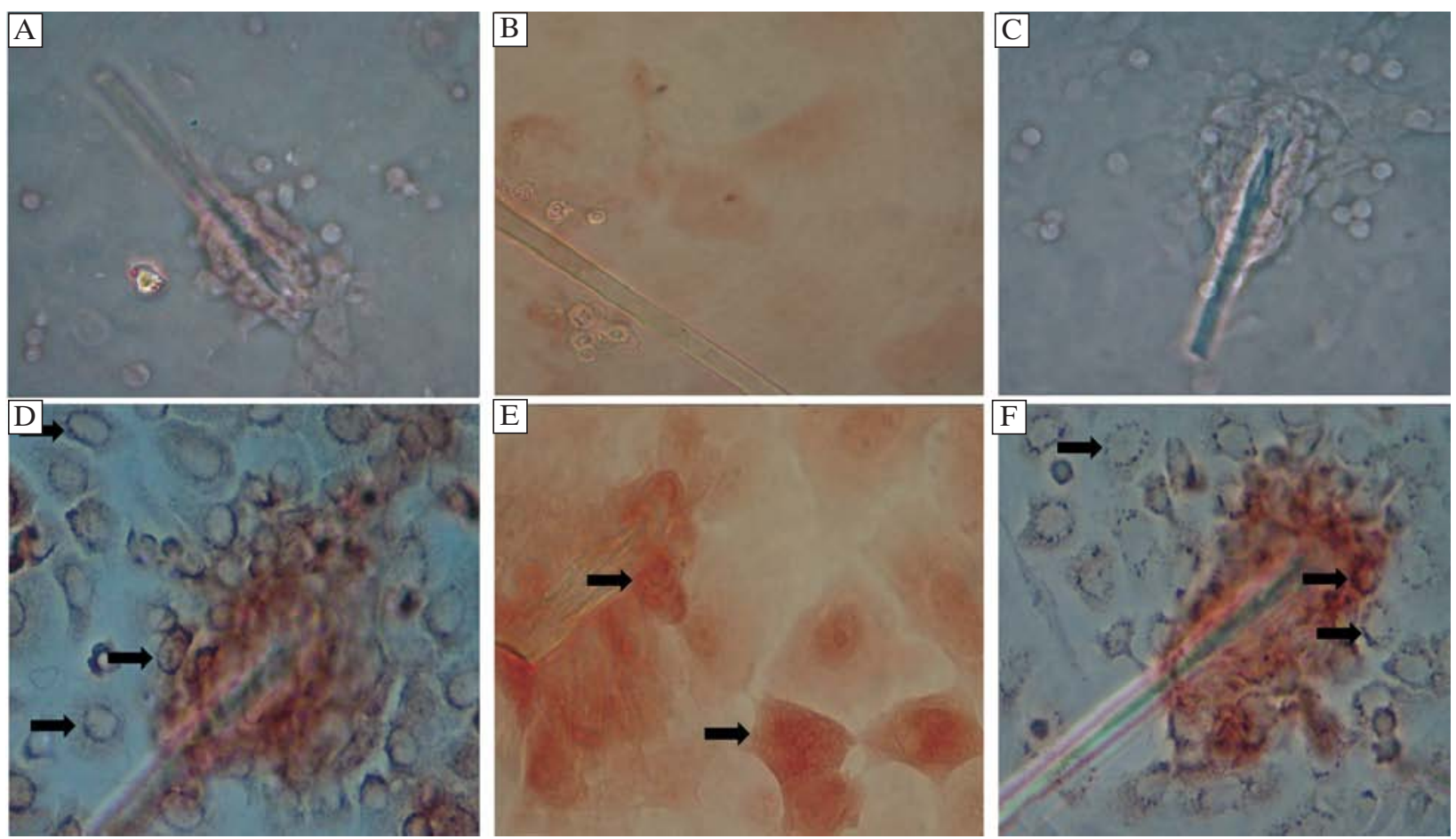

Figure 4. Immunohistochemical detection of trichohyalin, calretinin and K6hf in hair bulbs cultured for 72 hours; trichohyalin (negative - A, positive - D), calretinin (negative $-\mathbf{B}$, positive $-\mathbf{E}$ ) and K6hf (negative $-\mathbf{C}$, positive - F). Trichohyalin, calretinin and K6hf expression was observed in some cells attached to the hair shaft and in spread keratinocytes. Positive cells are shown by arrows. Magn. $(\mathbf{A}, \mathbf{B}, \mathbf{C}) \times 125 ;(\mathbf{D}, \mathbf{E}, \mathbf{F}) \times 400$

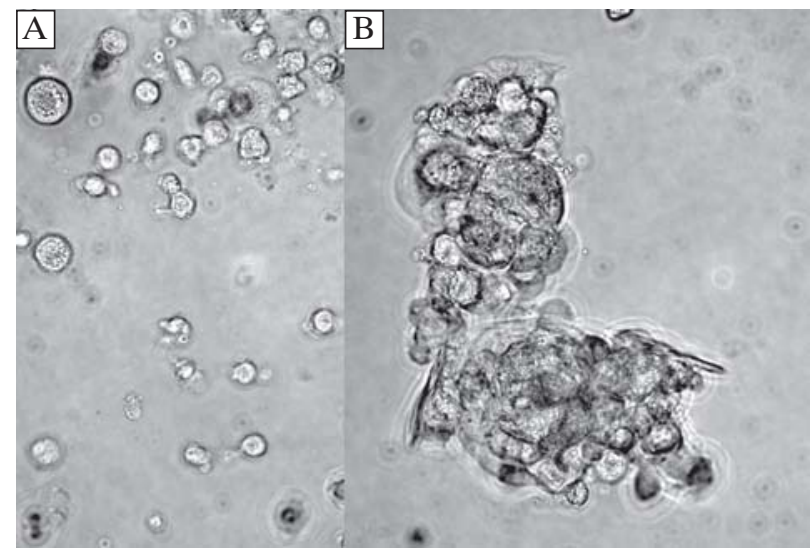

Figure 5. Keratinocytes growing from hair bulbs were transferred onto agarose layer and incubated in the standard medium (A) or medium enriched with $1.5 \mathrm{mM}$ $\mathrm{Ca}^{2+}(\mathbf{B})$ for 24 hours; phase contrast, $\times 125$. (A) cells were floating freely in the medium; (B) after elevation of calcium concentration cells formed large clusters

ter 24 hours. The effect was further increased by a rise in $\mathrm{Ca}^{2+}$ concentration but only after 24 hours' incubation. Culture in the standard medium for 12 hours had no effect on Kdap expression (Figure 6D), but the level of mRNA became slightly elevated after 24 hours' culture. $\mathrm{Ca}^{2+}$ enriched medium caused elevation of mRNA level for Kdap already after 12 hours and 24 hours.

\section{Expression of differentiation markers $m R N A$ in hair bulb-derived cells cultured on agarose layer is elevated in $\mathrm{Ca}^{2+}$-enriched medium}

In cells cultured in standard medium, mRNA level for involucrin (Figure 7A) was slightly elevated in comparison with freshly detached cells. $\mathrm{Ca}^{2+}$ enriched medium slightly but significantly increased the level of mRNA for involucrin after 12 hours; the effect after 24 hours of stimulation was much stronger. Culture in the standard medium increased filaggrin expression (Figure 7B) in comparison with freshly detached cells. mRNA expression after a rise in $\mathrm{Ca}^{2+}$ concentration was noticeable after 12 hours and had markedly risen after 24 hours. Culture in the standard medium had no effect on trichohyalin (Figure 7C) expression in comparison with cells analyzed immediately after detachment, but became elevated after $\mathrm{Ca}^{2+}$ stimulation both after 12 hours, and even more strongly after 24 hours' culture. The level of mRNA for Kdap (Figure 7D) was elevated in cells cultured in the standard medium for 24 hours, but after $\mathrm{Ca}^{2+}$ exposure was increased both after 12 hours and 24 hours.

\section{Discussion}

According to the classical electron microscopy description, the bulb region (hair bulb) contains the 


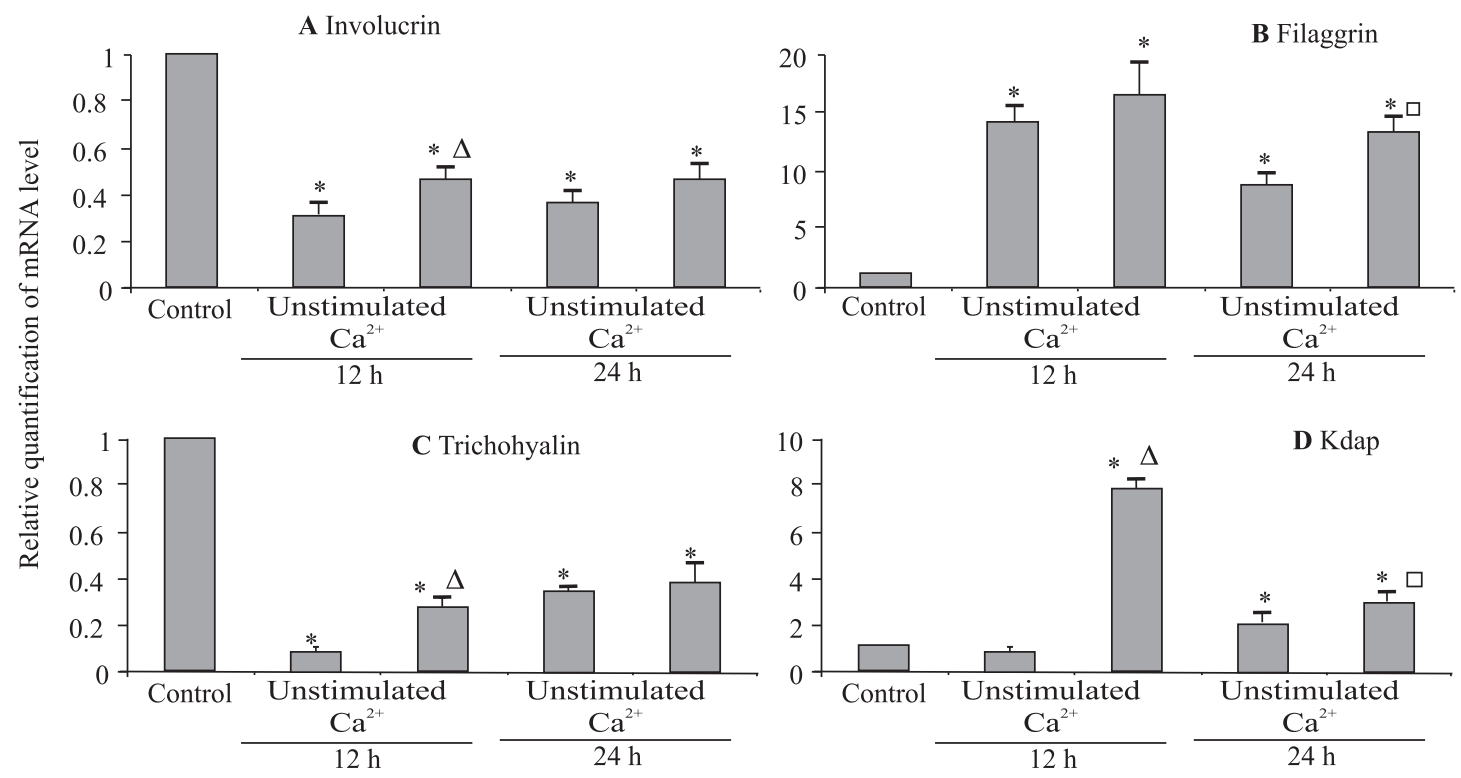

Figure 6. Relative quantification of (A) involucrin, (B) trichohyalin, (C) filaggrin and (D) Kdap mRNA level in whole hair bulbs cultured on agarose layer in the standard medium (unstimulated cultures) or $1.5 \mathrm{mM} \mathrm{Ca}^{2+}$ enriched medium. Bars \pm SE represent mean from five experiments. mRNA level in freshly isolated hair bulbs was set to 1 and served as a control. Statistical analysis was done with Wilcoxon-matched pair test. Asterisks mark significant statistical difference $(\mathrm{p}<0.05)$ in reference to control, triangles with reference to 12 hour unstimulated cultures and squares to 24 hour unstimulated cultures
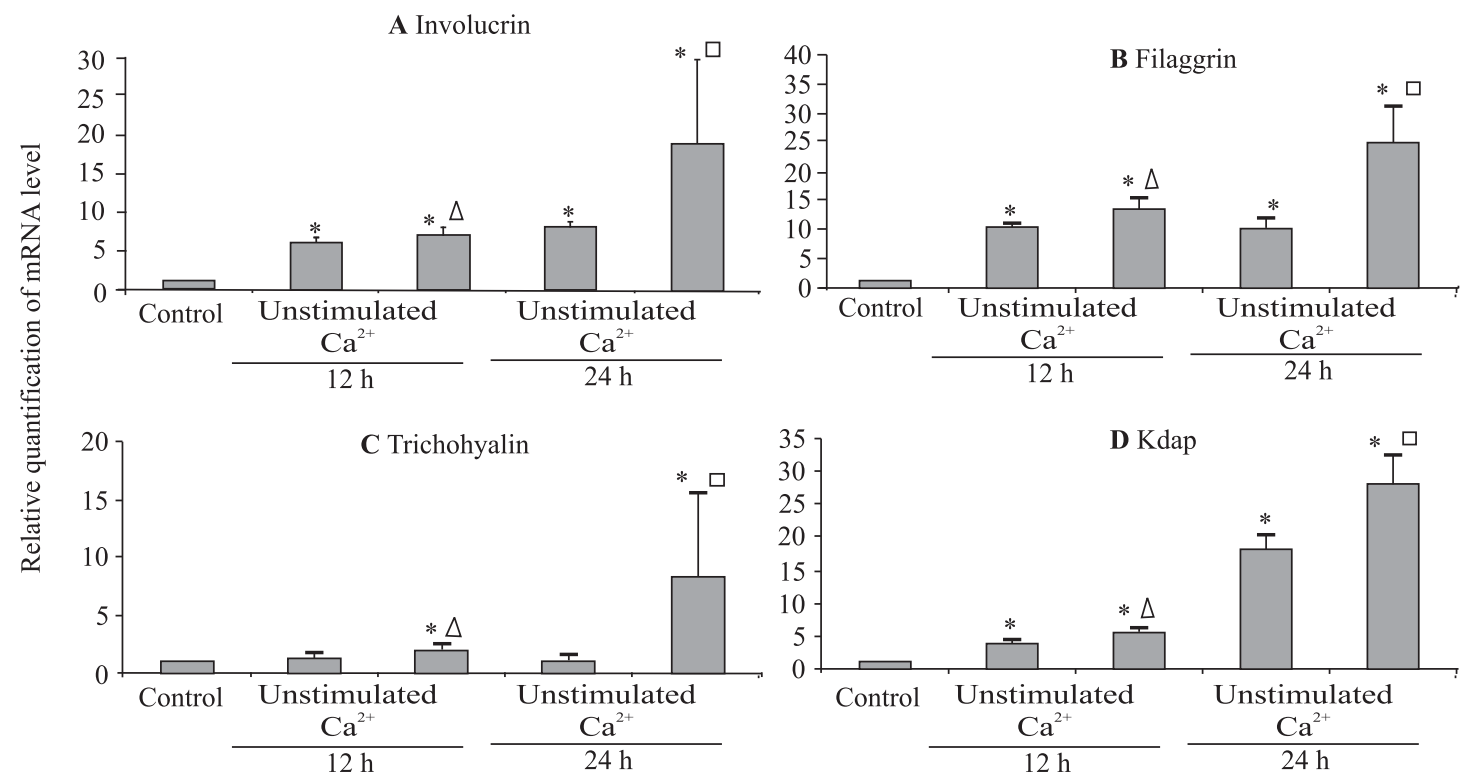

Figure 7. Relative quantification of (A) involucrin, (B) trichohyalin, (C) filaggrin and (D) Kdap mRNA level in hair bulb cells cultured on agarose layer in the standard medium (unstimulated cultures) or $1.5 \mathrm{mM} \mathrm{Ca}{ }^{2+}$ enriched medium. Bars \pm SE represent mean from five experiments. mRNA level from cells freshly harvested from primary cultures was set to 1 and served as a control. Statistical analysis was done with Wilcoxon-matched pair test. Asterisks mark significant statistical difference $(\mathrm{p}<0.05)$ in reference to control, triangles with reference to 12 hour unstimulated cultures and squares to 24 hour unstimulated cultures

germinal layer attached to the papilla, division region and the undifferentiated matrix from which derive all the cells forming the hair and the IRS [25]. Differen- tiation of IRS cells and the formation of trichohyalin droplets in human hairs begin in the mid bulb and upper bulb, but the rate of accumulation is greatest in 
Henle's layer, which is also the first to become keratinized [27]. In rat hairs, Huxley's layer does not show signs of differentiation at the intermediate height of the hair bulb, noticeable already in the Henle's layer [3].

Since hair bulbs are located at various levels in the skin, specimens isolated from its deep layer differed in length and, thus, in the degree of keratinization of IRS. The longest bulbs could even contain fragments of hair mid-segments, as defined in this and our previous paper [21].

Nevertheless, comparing the number of cells present in the hair bulbs and mid-segments of hairs $[3,25]$ there can be no doubt that the former predominated in our material.

For experiments, hair follicles in the anagen stage were used. During the catagen stage, the lower part of the follicle just under the bulge rapidly regresses, mainly by apoptosis of the hair matrix. In the telegen stage, the hair follicle is reduced to an epithelial strand bringing the dermal papilla into close proximity with the bulge [34].

Agarose gel has a distinct advantage as a supporting material if the three-dimensional structure of hair fragments is to be preserved because cells do not attach to it [35] and contact between keratinocytes and agarose does not interfere with keratinization [36, 37]. In our previous work, the response of hair mid-segments cultured in low and high $\mathrm{Ca}^{2+}$ medium on agarose was compared with that of monolayer cultures of mid-segment derived cells growing on plastic [21]. In the present work, the experimental design was modified and the response of whole hair bulbs kept on agarose was compared with that of keratinocytes which after outgrowing from hair bulbs were seeded on agarose and remained in suspension. Suspended cells reacted to raised $\mathrm{Ca}^{2+}$ concentration similarly to mid-segment cells in monolayer culture, but were inconvenient in use for immunocytochemical observations since they aggregated and formed clumps. Therefore, such studies were done on cells growing in monolayer cultures. Trichohyalin detected with AE 15 monoclonal antibody was present in cells from primary cultures of hair bulbs, presumably originating from the mid-region of hair bulbs in which Henle's and Huxley's cells commence formation of trichohyalin $[3,27]$. Cells reacting with anti-K6hf antibody were also present in primary cultures. They could originate from the companion layer, hair follicle matrix, or both [8]. Cells expressing calretinin, a specific marker for companion layer [11], were also detected in primary cultures but only after incubation in high calcium medium before fixation for 24 hours. According to experiments by Winsky and Kuźnicky, detection of calcium-binding proteins may be influenced by their calcium binding status [30]. Neither trichohyalin nor calretinin positive cells were detected in the secondary cultures. They presumably were lost during transfer.

Comparison of involucrin, filaggrin and Kdap expression observed in hair bulbs cultures in this work, and in mid-segment cultures published previously [21], indicate that their response was similar. Cells outgrowing from mid-segments cultured on plastic and from hair bulbs cultured on agarose layer reacted similarly to raised $\mathrm{Ca}^{2+}$ concentration, increasing expression of filaggrin, Kdap and involucrin. In both types of hair fragments kept on agarose with preserved 3-D structure, raised $\mathrm{Ca}^{2+}$ content in the culture medium stimulated expression of filaggrin and Kdap but inhibited expression of involucrin.

We have previously suggested that the inhibition of involucrin expression in the ORS is caused either by a factor released from the IRS or by cell-to-cell contact of the ORS with the IRS. Because cells of Henle's layer in mid-segments are in rats nearly completely keratinized [26], the inhibitory factor would have to be produced by Huxley's layer cells and secreted into the ORS through outgrowths of the specialized cells from the Huxley's layer [38]. These outgrowths pass through the Henle's layer and contact cells of the ORS [39], or more precisely, the companion layer cells [40] where they form gap-junction like structures [39].

We have also considered the possibility that such a factor is produced by companion cells either as their intrinsic property or under influence of contact with the cells of the Henle's layer. Recently, apigenin, a plant-derived flavonoid with skin cancer chemopreventive properties, has been found to inhibit involucrin expression during normal human keratinocyte differentiation [41]. Thus, a factor with similar properties could be produced in the IRS and act on the ORS, preventing their keratinization. Demonstrating that inhibition of ORS keratinization by contact with the IRS occurs both at the hair bulb and mid-segment level may simplify studies on the mechanism of inhibition, indicating that their separation during isolation procedure is unnecessary.

The trichohyalin molecule has a pair of calcium-binding domains [42, 43], but we have been unable to find any information on the influence of calcium on its expression. In this work, trichohyalin expression, similarly to that of involucrin, filaggrin and Kdap, was stimulated by $\mathrm{Ca}^{2+}$ in cells outgrowing from the hair bulbs, but decreased in whole hair bulbs kept on agarose. This contradictory result may reflect the difference in cell nutrition in both types of culture. Capillary vessels are present at the base of the hair papilla, 
but do not enter into it [44]. Therefore, the cells of the hair follicle matrix are supplied by physical, nutritional and informational flow from the cells of the papilla itself [3]. In 3-D agarose cultures of collagenase-isolated hairs, IRS would be devoid of contact with the papilla cells, and therefore its supply of nutrients and metabolism would decrease. ORS cells are, in situ, supplied by the dermal sheath which is removed during collagenase treatment. Thus, ORS cells in culture have free access to nutrients and their metabolism is not impaired, as evidenced by stimulation of filaggrin and Kdap expression [21].

ORS/IRS interface is probably a slippage plane for the upward movement of the growing hair. Thus, maintaining ORS cells in a non-keratinized state seems to be essential for hair shaft growth [7]. We suggest that deficiency of involucrin expression in ORS cells due to mechanical or humoral activity of IRS cells prevents terminal differentiation of ORS, since involucrin is essential for keratinization $[17,24]$. The mechanism that prevents ORS keratinization could protect the hair follicle against a rise in calcium level but could fail when calcium concentration within hair is insufficient. In patients suffering from hyperthyroidism, hyperparathyroidism and osteomalacia, hair concentration of calcium is elevated [45] but it does not affect hair follicle condition [46]. It should however be noted that in hypoparathyroidism hairs contain decreased amount of calcium [45] and are coarse and sparse [46]. Whether hair pathology in hypoparathyroidism is caused by a lack of inhibitory effect of calcium on involucrin expression with consequent keratinization of ORS requires further study.

\section{References}

1. Oshima H, Rochat A, Kedzia C, Kobayashi K, Barrandon Y. Morphogenesis and renewal of hair follicles from adult multipotent stem cells. Cell. 2001;104:233-245.

2. Orwin DFG. Cell differentiation in the lower outer sheath of the Romney wool follicle: A companion cell layer. Aust J Biol Sci. 1971;24:989-999.

3. Morioka K. Hair Follicle: differentiation under the electron microscope. An atlas. Tokyo: Springer-Verlag; 2005.

4. Cotsarelis G, Sun TT, Lavker RM. Label-retaining cells reside in the bulge area of pilosebaceous unit: implications for follicular stem cells, hair cycle, and skin carcinogenesis. Cell. 1990;6:1329-1337.

5. Lavker RM, Sun TT. Hair follicle stem cells: present concepts. J Invest Dermatol. 1995;104(5 Suppl):38S-39S.

6. Morris RJ, Liu Y, Marles L et al. Capturing and profiling adult hair follicle stem cells. Nat Biotechnol. 2004;22: 411-417.

7. Rogers GE. Structural and biochemical features of the hair follicle. In: Montagna W, Lobitz WC, eds. The Epidermis. New York: Academic Press; 1964:179-236.

8. Wang Z, Wong P, Langbein L, Schweizer J, Coulombe PA. Type II epithelial keratin $6 \mathrm{hf}$ (K6hf) is expressed in the com- panion layer, matrix, and medulla in anagen-stage hair follicles. J Invest Dermatol. 2003;121:1276-1282.

9. Mahony D, Karunaratne S, Rothnagel JA. The companion layer and outer root sheath of the anlagen hair follicle. Exp Dermatol. 1999;8:329-331

10. Winter H, Langbein L, Praetzel S. A novel human type II cytokeratin, K6hf, specifically expressed in the companion layer of the hair follicle. J Invest Dermatol. 1998;111:955-962.

11. Poblet E, Jimenez F, de Cabo C, Prieto-Martin A, SánchesPrieto $\mathrm{R}$. The calcium-binding protein calretinin is a marker of the companion cell layer of the human hair follicle. $\mathrm{Br}$ J Dermatol. 2005;152:1316-1320.

12. Hanakawa Y, Li H, Lin C, Stanley JR, Cotsarelis G. Desmogleins 1 and 3 in the companion layer anchor mouse anagen hair to the follicle. J Invest Dermatol. 2004;123:817-822.

13. Detmar M, Schaart FM, Blume U, Orfanos CE. Culture of hair matrix and follicular keratinocytes. J Invest Dermatol. 1993;101(1 Suppl):130S-134S.

14. Imcke E, Mayer-da-Silva A, Detmar M, Tiel H, Stadker R. Growth of human hair follicle keratinocytes in vitro. $\mathrm{J} \mathrm{Am}$ Acad Dermatol. 1987;17:779-786.

15. Schaart FM, Mayer-da-Silva A, Stadler R, Orfanos CE. In vitro culture of human hair follicular keratinocytes and their growth under various conditions. J Cutan Cosmet Aging Dermatol. 1990;1:175-191.

16. Weterings PJ, Verhagen H, Wirtz P, Vermorken AJ. Differentiation of human scalp hair follicle keratinocytes in culture. Virchows Arch B Cell Pathol Incl Mol Pathol. 1984; 45:255-266.

17. Candi E, Schmidt R, Melino G. The cornified envelope: a model of cell death in the skin. Nat Rev Mol Cell Biol. 2005; 6:328-340.

18. Ishida-Yamamoto A, Hashimoto Y, Manabe M, O'Guin WM, Dale BA. Distinctive expression of filaggrin and trichohyalin during various pathways of epithelial differentiation. $\mathrm{Br}$ J Dermatol. 1977;137:9-16.

19. Oomizu S, Sahuc F, Asahina K. Kdap, a novel gene associated with the stratification of the epithelium. Gene. 2000; 256:19-27.

20. Tsuchida M, Bonkobara M, McMillan JR. Characterization of Kdap, a protein secreted by keratinocytes. $J$ Invest Dermatol. 2004;122:1225-1234.

21. Niderla-Bielinska J, Jankowska-Steifer E, Moskalewski S. Keratinization of outer root sheath cells is prevented by contact with inner root sheath of rat follicle cells. Arch Dermatol Res. 2009;301;337-345.

22. Eckert RL, Rorke EA. Molecular biology of keratinocytes differentiation. Environ Health Perspect. 1989;80:109-116.

23. Rice RH, Green H. Presence in human epidermal cells of a soluble protein precursor of the cross-linked envelope: activation of the cross-linking by calcium ions. Cell. 1979;18:681-694.

24. Thacher SM, Rice RH. Keratinocyte-specific transglutaminase of cultured human epidermal cells: relation to cross-linked envelope formation and terminal differentiation. Cell. 1985;40:685-695.

25. Birbeck MS, Mercer EH. The electron microscopy of the human hair follicle. I. Introduction and the hair cortex. J Biophys Biochem Cytol. 1957;3:203-214.

26. Niderla-Bielinska J, Jankowska-Steifer E, Moskalewski S. Formation of spheroids composed of Henle layer cells and fat droplets in the cultures of rat hair follicles. Arch Dermatol Res. 2007;298:511-514.

27. Birbeck MS, Mercer EH. The electron microscopy of the human hair follicle. III. The inner root sheath and trichohyalin. J Biophys Biochem Cytol. 1957;3:223-230. 
28. Ishii Y, Tsutsui S, Doi K, Itagaki S. Hair follicles of young Wistar strain hairless rats: a histological study. $J$ Anat. 1997;191(Pt 1):99-106.

29. Glade MJ, Kanware YS, Hefley TJ. Enzymatic isolation of chondrocytes from immature rabbit articular cartilage and maintenance of phenotypic expression in culture. $J$ Bone Miner Res. 1991;6:217-226.

30. Winsky L, Kuźnicki J. Antibody recognition of calcium-binding proteins depends on their calcium-binding status. $J \mathrm{Neu}$ rochem. 1996;66:764-71.

31. Jiang M, Swann JW. Expression of calretinin in diverse neuronal populations during development of rat hippocampus. Neuroscience. 1997;81:1137-1154.

32. Manabe M, Yaguchi H, Iqbal Butt K et al. Trichohyalin expression in skin tumors: retrieval of trichohyalin antigenicity in tissues by microwave irradiation. Int J Dermatol. 1996; 35:325-329.

33. O'Guin WM, Sun TT, Manabe M. Interaction of trichohyalin with intermediate filaments: three immunologically defined stages of trichohyalin maturation. J Invest Dermatol. 1992;98:24-32.

34. Schneider MR, Schmidt-Ullrich R, Paus R. The hair follicle as a dynamic miniorgan. Curr Biol. 2009 Feb 10;19: R132-142.

35. Horwitz AL, Dorfman A. The growth of cartilage cells in soft agar and liquid suspension. J Cell Biol. 1970; 45: 434-438.

36. Alaminos M, Garzón I, Sánchez-Quevedo MC et al. Timecourse study of histological and genetic patterns of differentiation in human engineered oral mucosa. $J$ Tiss Eng Reg Med. 2007;1:350-359.

37. Schwartz JL. In vitro growth changes of oral human keratinocytes after treatment with carotenoids, retinoid and/or DMBA. Nutr Cancer. 1999;33:58-68.
38. Hoepke H. Die Haare. In: Möllendorf W ed. Handbuch der Mikroskopischen Anatomie Des Menschen. Berlin: Springer; 1927:66-88.

39. Clemmensen OJ, Hainau B, Hanstedt B. The ultrastructure of the transition zone between specialized cells ('Flugenzellen') of Huxley's layer of the inner root sheath and cells of the outer root sheath of the human hair follicle. Am J Dermatopath. 1991;13:264-270.

40. Langbein L, Rogers MA, Praetzel S, Aoki N, Winter H. A novel epithelial keratin, hK6irs1, is expressed differentially in all layers of the inner root sheath, including specialized Huxley cells (Flügenzellen) of the human hair follicle. J Invest Dermatol. 2002;118:789-799.

41. Balasubramianian S, Zhu L, Eckert RL. Apigenin inhibition of involucrin gene expression is associated with a specific reduction in phosphorylation of protein kinase C Tyr ${ }^{311}$. J Biol Chem. 2006;281:36162-36172.

42. Fietz MJ, Mclaughlan CJ, Campbell MT, Rogers GE. Analysis of the sheep trichohyalin gene: potential structural and calcium-binding roles of trichohyalin in the hair follicle. J Cell Biol. 1993;121:855-865.

43. Lee S-C, Kim I-G, Marekov LN, O'Keefe EJ, Parry DAD, Steinert PM. The structure of human trichohyalin. J Biol Chem. 1993;268:12164-12176.

44. Roth SI, Helwig EB. The cytology of the dermal papilla, the bulb, and the root sheaths of the mouse hair. $J$ Ultrastruct Res. 1964;11:33-51.

45. Miekeley N, de Fortes Carvalho LM, Porto di Silveira CL, Lima MB. Elemental anomalies in hairs as indicators of endocrinologic pathologies and deficiencies in calcium and bone metabolism. J Trace Elem Med Biol. 2001;15:46-55.

46. Jabbour SA. Cutaneous manifestations of endocrine disorders: a guide for dermatologists. Am J Clin Dermatol. 2003; $4: 315-331$. 